\title{
Perspectivas de la Educación Contable Desafíos para el reconocimiento de los espacios socioambientales en los programas de Contaduría Pública en la ciudad de Medellín
}

\author{
Perspectives of Accounting Academic Programs: Challenges \\ for the Recognition of Socio-Environmental Spaces in Public \\ Accounting Programs in Medellín
}

Recibido: 06-02-2016 • Aprobado: 28-05-2016 • Página inicial: 207 - Página final: 241

\author{
Leidy Jhojana Usma Zuleta*
}

Sara Torres Pérez**

\begin{abstract}
Resumen: Este artículo pretende analizar la contribución de la educación contable en los estudiantes de Contaduría Pública de la ciudad de Medellín, con el fin de reconocer los espacios socio-ambientales en los que habitan y se desarrollan personal y profesionalmente. Para esto, se presenta una conceptualización sobre el término espacio socio-ambiental; se realiza una caracterización desde los contenidos curriculares, los perfiles profesionales y las líneas de investigación, con el propósito de exponer sus aproximaciones socio-ambientales. Finalmente, se exponen y analizan algunas ideas sobre el aporte académico y sentires delos estudiantes de Contaduría Pública en la discusión socio-ambiental en Colombia, particularmente en la ciudad de Medellín donde se realiza el estudio.
\end{abstract}

Palabras clave: educación y formación contable, espacios socio-ambientales, currículo.
Abstract: The intent of this paper is to analyze the contribution of accounting programs to public accounting students in Medellín in order to recognize the socio-environmental spaces in which they live and develop professionally. To this end, a conceptualization of the term "socio-environmental space" is offered. Similarly, a characterization based on curricular contents, professional profiles and research lines is performed in order to present their socio-environmental approach. Finally, we present and analyze some ideas about the academic contribution of public accounting and accounting students' perspectives within the socio-environmental debate in Colombia, particularly in Medellín, which is where the study is performed.

Keywords: accounting education and training, social and environmental areas, curriculum.

\footnotetext{
* Contadora Pública y asistente de investigación Grupo de Investigación Observatorio Público del Tecnológico de Antioquia, Medellín - Colombia. jhojausma@ hotmail.com

** Contadora Pública y asistente de Auditoría de Price Waterhouse Coopers, Medellín - Colombia. saristorresperez@hotmail.com
} 


\section{Perspectives de l'enseignement comptable Défis pour la reconnaissance des espaces socio- environnementaux dans les programmes de la comptabilité publique dans la ville de Medellín}

Résumé: cet article vise à analyser la contribution de l'enseignement comptable dans les étudiants de la comptabilité publique de la ville de Medellín, afin de reconnaître les espaces socio-environnementales dans les habitants et se développent personnel et professionnel. Pour cela, on présente une conceptualisation sur le terme "espace socio-environnementale; On procède à une caractérisation depuis les contenus pédagogiques, des profils professionnels et les lignes de recherche, dans le but d'exposer leurs approches socio-environnementales. Enfin, sont exposés et analyse certaines idées sur la contribution académique et sentires des étudiants de la comptabilité publique, à la discussion socio-environnementale en Colombie, en particulier dans la ville de Medellín où s'effectue l'étude.

Mots-clés:Éducation etformation comptable, espaces socio-environnementaux, programme d'étude.

\section{Perspectivas para o ensino de contabilidade. Desafios para o reconhecimento dos factores socioeconómicos espaços ambientais nos programas de contabilidade pública na cidade de Medellín}

Resumo: este artigo tem por objetivo analisar a contribuição do ensino de contabilidade em estudantes de contabilidade pública da cidade de Medellín, a fim de reconhecer os espaços de sócio-ambiental em que vivem e a desenvolver pessoal e profissionalmente.Para isso, apresenta uma conceituação sobre o termo espaço sócio-ambiental; realizada a uma caracterização do conteúdo do currículo, perfis profissionais e as linhas de pesquisa, com o objetivo de expor as suas abordagens sócio-ambiental. Finalmente, descreve e analisa algumas ideias sobre o acadêmico e sentires delos alunos de contabilidade pública no debate sócio-ambiental na Colômbia, particularmente na cidade de Medellín onde o estudo é realizado.

Palavras-chave: A educação e a formação de contabilidade, espaços sócioambiental, currículo. 


\section{Introducción}

La Contaduría Pública en Colombia es una profesión liberal que otorga fe y genera confianza pública en la sociedad, aspectos que permiten visualizar al profesional en el espacio que se desarrolla como un individuo consciente de las realidades y de las situaciones que lo rodean. Así pues, ante la educación y la formación contable de ese profesional, se considera de gran importancia suscitar por medio de los currículos el reconocimiento de los espacios socioambientales, ya que pueden considerarse, entre muchos otros, como elemento de ruta para que el individuo logre identificar y comprender su responsabilidad como ser crítico-reflexivo y transformador de las realidades que no atañen exclusivamente los aspectos económicos y financieros a los que la profesión comúnmente se asocia.

La preocupación por el reconocimiento de lo socio-ambiental dentro de los programas de Contaduría Pública surge a partir de la experiencia de las autoras dentro de su proceso de formación como estudiantes de Contaduría Pública en la ciudad de Medellín, más específicamente en la Institución Universitaria Politécnico Colombiano Jaime Isaza Cadavid. Durante dicho proceso fue posible identificar un sinnúmero de inconformidades que se reducen a la actitud desinteresada por parte de los estudiantes de Contaduría respecto de las problemáticas, conflictos y situaciones críticas por las que atraviesa el mundo actualmente, mundo que representa el territorio que forma parte vital de su desarrollo profesional y personal, y que merece, por parte del individuo en mención, un alto grado de interés, consideración y reconciliación.

Así pues, es menester discutir y problematizar la incidencia de la educación contable y sus dinámicas dentro de los procesos educativos y formativos de las Instituciones de Educación Superior (IES) y universidades de la ciudad de Medellín, con el fin de identificar y analizar su contribución al compromiso de entregar a la sociedad un ser consciente de ella, que se proponga defenderla y transformarla.

En ese orden de ideas, es pertinente hablar de un espacio socio-ambiental, término direccionado para esta investigación como el ámbito territorial y simbólico, en el cual se conciben relaciones y transformaciones sociales mediante los sujetos, relaciones que representan la construcción y la intencionalidad de las voluntades y de los conocimientos, provocando que los sujetos sean conscientes de la responsabilidad inherente que poseen consigo mismos, con el otro y con la conservación de los elementos físicos y naturales que contiene el ambiente. 


\section{Contexto usma L y yorms s.}

Debido a esta pretensión, es imperativo pues realizar una caracterización de los contenidos curriculares y perfiles de formación de los programas de Contaduría Pública de la ciudad de Medellín respecto de sus contenidos socio-ambientales. También caracterizar las líneas de investigación en materia socio-ambiental que se trabajan al interior de los grupos de investigación adscritos a los programas de Contaduría Pública de la ciudad de Medellín. Y además, un análisis sobre el aporte académico que han realizado estudiantes de Contaduría Pública a la discusión socio-ambiental en la ciudad de Medellín.

\section{Metodología}

Este artículo aborda un tipo de investigación cualitativa que evidencia la vía para comprender y analizar la contribución de la educación contable a los estudiantes de Contaduría Pública de la ciudad de Medellín para reconocer los espacios socio-ambientales en los que habitan y se desarrollan personal y profesionalmente; la intencionalidad metodológica recae en el análisis e interpretación de las características y comportamientos que se presentan en los sujetos contables dentro de las realidades sociales y humanas, apoyado en el análisis estadístico y reconociendo la importancia del mismo para el análisis de los resultados más importantes.

Se empleó un método hermenéutico, es decir, que es la posibilidad de interpretar categorías de análisis, tanto previstas como emergentes, que permiten analizar la contribución que hace la educación contable a los estudiantes de Contaduría Pública de la ciudad de Medellín, para reconocer los espacios socio-ambientales en los que habitan y se desarrollan personal y profesionalmente, asunto que se ha determinado como el propósito principal de esta investigación.

El proceso de investigación recurrió a estudiantes de Contaduría Pública mediante una encuesta aplicada por medio de un cuestionario, en la cual se tomó como muestra de carácter intencionada a estudiantes de últimos semestres de las diferentes IES y universidades de la ciudad de Medellín, ya que ellos tienen una larga trayectoria de estudios, lo cual facilitará el análisis de sus contribuciones, sus pensares y sus sentires sobre la discusión socio-ambiental. Además, se recurrió a fuentes documentales que contengan información sintetizada y organizada, con el fin de ampliar el contenido respecto de las fuentes orales, es decir, que se realizará un proceso de triangulación de la información. 


\section{Resultados}

\section{Caracterización de los contenidos curriculares y los perfiles profesionales de los programas de Contaduría Pública en la ciudad de Medellín}

Algunas discusiones se han enmarcado en torno a la intencionalidad de los currículos, razón de ello da la concepción positivista del Siglo XX, en la cual el currículo obedece a la institucionalización y a la formalización dentro de las dinámicas de control social e industrialización. "Así, el currículo adquiere centralidad con un interés exclusivamente técnico de control actuacional, construido a la usanza de la administración cientifica propia de la industria, sobre la racionalidad de mínimo costo y máximo beneficio" (Martínez, 2007, p. 59). Sin embargo, y rompiendo con laa concepción reduccionista que aporta el positivismo, bajo la noción del pensamiento crítico el currículo se concibe como la carrera de la vida que evoca su etimología del latín. ${ }^{1}$ Respecto de esto:

(...) el currículum comporta significados que van mucho más allá de aquellos a los que las teorías tradicionales lo redujeron. El currículum es lugar, espacio, territorio, relación de poder, trayectoria, viaje, recorrido, contradicción, autobiografía, consensos y disensos, construcción permanente de relaciones identitarias, es texto y contexto, praxis social, discurso y documento (p.62).

Una vez enunciadas estas concepciones, es preciso ubicar el currículo y sus elementos (tales como el perfil profesional y los programas de estudio) en un ámbito académico actual, donde “(...) lo curricular debe obedecer a ciertos principios, como la pertinencia, la flexibilidad, la integralidad, la interdisciplinariedad y la etnicidad" (Rojas y Ospina, 2011, p.56).

En vía a lo anterior, para esta investigación es pertinente realizar una caracterización de las asignaturas que sugieren contenidos sociales y/o ambientales en los programas de estudios de Contaduría Pública. Aunque esta acción no permite deducir, en primera instancia, si una IES y/o universidad propicia el reconocimiento de los espacios socio-ambientales, sí permite al lector identificar características que lo orienten sobre la educación y a la formación del programa.

Currículo: de la loc. lat. curriculum vitae; literalmente carrera de la vida. 


\section{Conterto usma L y yomess s.}

Así pues, para el análisis y la interpretación de los perfiles profesionales y los contenidos académicos, se relacionan las categorías de análisis utilizadas por las autoras:

- Ciencias sociales

- Formación ética y humanística

- Responsabilidad social

- Compromiso socio-ambiental

- Formación integral

En la Tabla 1 se facilitará la información sobre los perfiles profesionales y los contenidos académicos de los pregrados de Contaduría Pública ofertados por las IES y universidades de la ciudad de Medellín, información abordada desde las estadísticas del Sistema Nacional de la Educación Superior -SNIES-.

Tabla 2

Caracterización de los Perfiles de Contaduría Pública de las IES y universidades en la Ciudad de Medellín

IES y/o
Universidad Perfil Profesional Análisis Categorial

Corporación

Universitaria

Adventista
El aspirante a Contador Público deberá estar informado de la actualidad nacional e internacional, así como poseer conocimiento y gusto por las Ciencias Sociales, las Matemáticas, Estadística e Idiomas. Además, el aspirante deber poseer la capacidad de concentración, creatividad, una actitud analítica, interés por la investigación, la interpretación y el manejo de datos, así como disposición para trabajar en equipo.
El gusto por las ciencias sociales, descrito en el perfil profesional de esta Institución, puede dar vía a que en sus contenidos académicos existen énfasis en las ciencias sociales. Sin embargo, como se menciona en un sentido del gusto, se puede interpretar en un sentido personal mas no adquirido por la educación y formación. 


\begin{tabular}{ccc}
\hline IES y/o & Perfil Profesional & Análisis Categorial \\
Universidad
\end{tabular}

Corporación

Universitaria Americana
Es un profesional con formación ética y responsabilidad social, capaz de analizar problemas y formular soluciones, desempeñándose para trabajar en equipo y ser un profesional con liderazgo. Está capacitado para laborar en distintas organizaciones públicas, privadas, regionales y locales en las áreas contables, financiera, fiscal, tributaria, control, aseguramiento social y ambiental, sistemas de información, docencia e investigación. Es además analítico, creativo, estratégico y competente para diseñar, administrar y evaluar información financiera $\mathrm{y}$ no financiera.
Esta Institución profesa que sus profesionales son capaces de analizar problemas y formular soluciones debido a su formación en ética y responsabilidad social. Siendo estas razones para tener en cuenta su perfil como uno que va en concordancia con la categoría de análisis responsabilidad social. Pues se puede deducir que a partir de allí, el profesional puede desempeñarse y tomar decisiones sobre su accionar teniendo en cuenta el contexto de la sociedad.
Corporación Universitaria de Ciencia y Tecnología de Colombia
El Contador Público de la Corporación Universitaria de Ciencia y Tecnología de Colombia, estará preparado para administrar los procesos contables de una organización, buscando implementar las mejores estrategias de negociación que le permitan optimizar estos procesos a través de la constante innovación de conceptos comerciales que sean beneficiosos a nivel económico y competitivo con el fin de generar un alto valor a las empresas.
El énfasis del perfil profesional de esta Institución va en contravía a las categorías de análisis para esta investigación, pues describe una formación sobre el saber del trabajo finalizado con un interés general económico. Es así que no aplica intereses respecto de contenidos socio-ambientales.
Corporación

Universitaria de Ciencia

y Desarrollo

Uniciencia
Programa de Contaduría Pública no vigente en la ciudad de Medellín. 


\begin{tabular}{|c|c|c|}
\hline $\begin{array}{c}\text { IES y/o } \\
\text { Universidad }\end{array}$ & Perfil Profesional & Análisis Categorial \\
\hline $\begin{array}{l}\text { Corporación } \\
\text { Universitaria } \\
\text { Remington }\end{array}$ & $\begin{array}{l}\text { El profesional de Contaduría } \\
\text { Pública que se forma en Unire- } \\
\text { mington Corporación Univer- } \\
\text { sitaria es una persona íntegra } \\
\text { en valores, constructor de con- } \\
\text { fianza, comprometido con la } \\
\text { sociedad, las organizaciones y } \\
\text { el medio ambiente. Garantiza } \\
\text { la eficacia y rigurosidad en los } \\
\text { sistemas de información y pro- } \\
\text { cesos contables dirigidos al aná- } \\
\text { lisis y diagnóstico financiero y } \\
\text { estratégico de la Organización. } \\
\text { Propone alternativas de cam- } \\
\text { bio de los sistemas contables, } \\
\text { en concordancia con la realidad } \\
\text { de la internacionalización que } \\
\text { conlleva a profundas modifica- } \\
\text { ciones en el ejercicio de la Con- } \\
\text { taduría Pública. }\end{array}$ & $\begin{array}{l}\text { El profesional de la Corpora- } \\
\text { ción Universitaria Remington } \\
\text { es pensado desde los términos } \\
\text { de responsabilidad socio-am- } \\
\text { biental, pues en su perfil profe- } \\
\text { sional abogan por que éste sea } \\
\text { comprometido con la sociedad, } \\
\text { las organizaciones y el medio } \\
\text { ambiente. Es por esto que apli- } \\
\text { ca con la categoría de análisis } \\
\text { compromiso con la sociedad y } \\
\text { medio ambiente. }\end{array}$ \\
\hline
\end{tabular}

El Contador Público puede comprender y proponer nuevas alternativas de solución a las problemáticas relacionadas con Fundación las ciencias contables, financieEscuela ras y tributarias existentes en Colombiana de las organizaciones, que permiMercadotecnia -Escolmetan una efectiva toma de decisiones, generador de confianza pública, con visión gerencial, con competencias en el manejo y aplicación de Normas Internacionales de Contabilidad (NIC) y dominio conceptual sobre las tendencias de la disciplina.
Aunque el profesional de esta Institución puede llegar a ser generador de confianza pública, según su perfil, sus perspectivas sobre este compromiso van direccionados a la visión general de las ciencias contables, financieras y tributarias. Por lo tanto, éste perfil no encuentra relación con las categorías de análisis. 


\begin{tabular}{ccc}
\hline IES y/o & Perfil Profesional & Análisis Categorial \\
Universidad &
\end{tabular}

Fundación

Universitaria

María Cano
El programa de contaduría pública de la Fundación Universitaria María Cano forma sus Contadores Públicos con valores éticos, capaces de ejercer liderazgo en equipos interdisciplinarios, con profundos saberes y sólidos conocimientos en la ciencia y el control, el derecho contable, creativo, prospectivo, interdisciplinario, conocedores del entorno y realidad nacional, con un sentido crítico que les permita tomar decisiones, participar de los más altos niveles organizacionales, resolver conflictos, y analizar y preparar la información para la toma de decisiones, con fortaleza investigativa, a través del método de enseñanza con proyección internacional, que combine la ciencia y la tecnología en su hacer diario y con una clara conciencia ambiental y social, comprometido con el desarrollo político y social del país.
La formación integral es una de las categorías de análisis que aplica este perfil junto con el compromiso con la sociedad y el medio ambiente. Pues, la Fundación Universitaria María Cano promete un Contador Público formado desde varias perspectivas, que van desde lo crítico, investigativo, social $\mathrm{y}$ contable hasta formar una conciencia ambiental y social comprometido con el desarrollo político del país. 


\begin{tabular}{|c|c|c|}
\hline $\begin{array}{c}\text { IES y/o } \\
\text { Universidad }\end{array}$ & Perfil Profesional & Análisis Categorial \\
\hline $\begin{array}{l}\text { Institución } \\
\text { Universitaria } \\
\text { Salazar y } \\
\text { Herrera }\end{array}$ & $\begin{array}{l}\text { El Profesional en Contaduría } \\
\text { Pública de la Institución Univer- } \\
\text { sitaria Salazar y Herrera, será un } \\
\text { egresado de la Educación Supe- } \\
\text { rior, cuya formación integral } \\
\text { basada en principios humanís- } \\
\text { ticos, le permite incorporar los } \\
\text { conocimientos, habilidades y } \\
\text { destrezas para ser competente } \\
\text { en el reconocimiento y reve- } \\
\text { lación de hechos económicos, } \\
\text { contables y financieros, y ase- } \\
\text { guramiento de la información, } \\
\text { con pensamiento crítico, lógico } \\
\text { y analítico en diferentes contex- } \\
\text { tos normativos y en el marco de } \\
\text { la globalización. }\end{array}$ & $\begin{array}{l}\text { Aunque a simple vista se pue- } \\
\text { da identificar en la descripción } \\
\text { de este perfil una formación } \\
\text { integral basada en principios } \\
\text { humanísticos, estos van en } \\
\text { contraposición de su desem- } \\
\text { peño pues refiere, además, que } \\
\text { su formación está direccionada } \\
\text { dentro de las lógicas de la glo- } \\
\text { balización. }\end{array}$ \\
\hline
\end{tabular}

Politécnico

Colombiano

Jaime Isaza

Cadavid
El contador público del Politécnico Colombiano Jaime Isaza Cadavid es un profesional con formación integral y competencias para diagnosticar la situación contable, financiera $y$ administrativa del ente económico y proponer soluciones a los problemas encontrados. El profesional en contaduría pública puede desempeñarse en diferentes actividades profesionales de carácter contable en los sectores público y privado: revisor fiscal, contralor, jefe de contabilidad, jefe de costos, asesor contable y tributario, consultor, auditor externo, auditor interno, auditor tributario, investigador contable, jefe de impuestos, director de control interno y docente universitario.
El perfil del Politécnico Colombiano Jaime Isaza Cadavid aboga por un profesional capaz de realizar diagnósticos; aunque sugiere que puede proponer soluciones a problemas encontrados, refiere su profesional en algunos campos de acción sin describir sus capacidades. Por lo tanto, no aplica a las categorías de análisis. 


\begin{tabular}{ccc}
\hline IES y/o & Perfil Profesional & Análisis Categorial \\
Universidad &
\end{tabular}

Tecnológico de Antioquia

Universidad Autónoma
El Contador Público del Tecnológico de Antioquia, es un ser humano integral, formado con sentido ético y responsabilidad social y con dominio de las temáticas, para el buen desempeño profesional. Competente en el control, gestión gerencial, y aportante en la toma de decisiones y con manejo de los sistemas de información en las organizaciones tanto públicas como privadas.
Este perfil da cuenta del interés por formar un profesional integral con sentido ético y responsabilidad social, categorías de análisis de esta investigación. Sin embargo, cabe resaltar una falta de descripción del perfil profesional pues no es muy claro y puede dejar baches en su interpretación.
Será una persona con habilidades académicas, profesionales y sociales, capaz de participar en la solución de conflictos a través de procesos dialógicos; de emitir juicios profesionales sobre la continuidad de las organizaciones de diverso orden, soportados en el diseño, la implementación y la administración de sistemas de información contable y sistemas de control, atendiendo las necesidades de información de los agentes que participan de la vida económica de la nación, orientando su labor a la protección del interés público, en los sectores público, privado y social y en los ámbitos local, nacional e internacional.
El perfil de la Universidad Autónoma Latinoamericana -Unaula- es considerado por las autoras como el más completo en su descripción, pues recoge desde el pensamiento crítico hasta los conocimientos contables, es decir, la categoría de análisis de formación integral, llevándolo a un campo de acción consciente de su papel en las organizaciones y al mismo modo, con la naturaleza y la sociedad. Demuestra así un compromiso integral para con su profesional y el país. 
Usma, L. y Torres, S.

\begin{tabular}{|c|c|c|}
\hline $\begin{array}{c}\text { IES y/o } \\
\text { Universidad }\end{array}$ & Perfil Profesional & Análisis Categorial \\
\hline $\begin{array}{c}\text { Universidad } \\
\text { Autónoma }\end{array}$ & $\begin{array}{l}\text { Consciente que su saber se ins- } \\
\text { cribe en el campo de las ciencias } \\
\text { económicas, reconoce su com- } \\
\text { promiso con la tarea de informar } \\
\text { y controlar los procesos de ge- } \\
\text { neración, distribución y redistri- } \\
\text { bución de la riqueza, además del } \\
\text { uso productivo y responsable de } \\
\text { los recursos. } \\
\text { Sus actuaciones estarán regidas } \\
\text { por los más altos principios éticos } \\
\text { y valores morales, como cons- } \\
\text { tructor de confianza pública que } \\
\text { es. Será un ciudadano respetuoso } \\
\text { de la diferencia y promotor de } \\
\text { niveles de convivencia y de un } \\
\text { orden social justo, equitativo e } \\
\text { incluyente. } \\
\text { Adicionalmente, será sensible } \\
\text { con el entorno social y natural, } \\
\text { defensor del principio de igual- } \\
\text { dad biocéntrica como condición } \\
\text { necesaria para la preservación del } \\
\text { planeta y de la especie humana. }\end{array}$ & \\
\hline
\end{tabular}

Formar profesionales bajo una filosofía humanista, con una amplia capacidad para proponer desde los principios éticos, cristianos y científicos un ejercicio de la Contaduría que asegure la transparencia, la comprensibi-

Universidad

Católica Luis

Amigó Funlam lidad, la utilidad y pertinencia de la información contable y financiera de las organizaciones, en el contexto de la fe pública, mediante la generación de la confianza pública, que permitan actuar con espíritu crítico, con compromiso personal y social para la búsqueda de soluciones de los problemas socio-económicos del país.
La filosofía humana, la transparencia, la fe y la confianza públicas direccionan a que el profesional de esta Institución sea comprometido con él mismo y la sociedad en la que se desarrolla. Sin embargo, aboga para que estos elementos ayuden en la solución de problemas socio-económicos, haciendo falta más claridad en dicho término. Este perfil profesional aplica a la categoría de análisis formación ética y humanística. 


\begin{tabular}{|c|c|}
\hline $\begin{array}{c}\text { IES y/o } \\
\text { Universidad }\end{array}$ & Análisis Categorial \\
\hline $\begin{array}{l}\text { Universidad } \\
\quad \text { CES }\end{array}$ & $\begin{array}{l}\text { Programa de Contaduría Pública no vigente en la ciudad de } \\
\text { Medellín. }\end{array}$ \\
\hline $\begin{array}{c}\text { Universidad } \\
\text { Cooperativa de } \\
\text { Colombia }\end{array}$ & $\begin{array}{ll}\text { El profesional de Contaduría } & \text { Esta universidad propone un } \\
\text { Pública de la Universidad Coo- } & \text { profesional con una formación } \\
\text { perativa de Colombia es un } & \text { integral. Lo cual permite dilu- } \\
\text { profesional integral, líder con } & \text { cidar una responsabilidad so- } \\
\text { sentido de responsabilidad so- } & \text { cial y ética con la sociedad. Sin } \\
\text { cial, ético, solidario innovador, embargo, se puede quedar en el } & \text { emborion } \\
\text { creativo y adaptable al cambio. } & \text { limbo sus habilidades, pues, no } \\
\text { Estará en capacidad de dar Fe } & \text { es muy clara la descripción. } \\
\text { Pública de los actos propios de } & \\
\text { la disciplina contable. } & \end{array}$ \\
\hline $\begin{array}{l}\text { Universidad de } \\
\text { Antioquia }\end{array}$ & $\begin{array}{ll}\text { El contador público de la Uni- } & \text { La Universidad de Antioquia } \\
\text { versidad de Antioquia es una } & \text { ofrece en su perfil una signifi- } \\
\text { persona con significativa ca- } & \text { cativa descripción de las habi- } \\
\text { pacidad para desenvolverse } & \text { lidades de su profesional, sin } \\
\text { en el medio contable. Muestra } & \text { embargo, es un poco confuso el } \\
\text { habilidades para el análisis de } & \text { énfasis de su formación. Aun- } \\
\text { problemas, contribuyendo al que se describe como un ser } & \text { que } \\
\text { desarrollo de los procesos que } & \text { que contribuye a la solución } \\
\text { encaucen soluciones adecua- } & \text { de problemas no se identifica } \\
\text { das y oportunas. Es razonador, el tipo de problemas a que se } \\
\text { creativo cuando se trata de di- } \\
\text { seños, tiene sólida formación } \text { ninguna categoría de análisis. } \\
\text { conceptual, es diligente y de- } \\
\text { dicado a su trabajo. Manifiesta } \\
\text { deseos de superación y perfec- } \\
\text { cionamiento en los campos per- } \\
\text { sonal y profesional. }\end{array}$ \\
\hline
\end{tabular}




\begin{tabular}{|c|c|c|}
\hline $\begin{array}{c}\text { IES y/o } \\
\text { Universidad }\end{array}$ & Perfil Profesional & Análisis Categorial \\
\hline $\begin{array}{l}\text { Universidad de } \\
\text { Medellín }\end{array}$ & $\begin{array}{l}\text { El egresado de Contaduría } \\
\text { Pública de la Universidad de } \\
\text { Medellín tendrá la capacidad } \\
\text { de desenvolverse en entornos } \\
\text { económicos y tecnológicos glo- } \\
\text { balizados, con el fin de solu- } \\
\text { cionar desde sus competencias } \\
\text { técnico-científicas problemas } \\
\text { concernientes a la construcción, } \\
\text { control y certificación de infor- } \\
\text { mación, para comunicarla de } \\
\text { manera efectiva como conoci- } \\
\text { miento útil en el proceso de de- } \\
\text { sarrollo de oportunidades pre- } \\
\text { sentes y futuras de las personas } \\
\text { y las organizaciones, especial- } \\
\text { mente en los campos financiero } \\
\text { y tributario. } \\
\text { Además, el Contador Público } \\
\text { de la Universidad de Medellín, } \\
\text { tendrá plena conciencia de la } \\
\text { importancia e impacto social y } \\
\text { humano del ejercicio de la pro- } \\
\text { fesión y la ejercerá con los más } \\
\text { altos estándares éticos generan- } \\
\text { do en los usuarios de sus ideas, } \\
\text { plena confianza en la integridad } \\
\text { de los resultados obtenidos so- } \\
\text { bre la base de la constante actua- } \\
\text { lización de sus conocimientos, } \\
\text { de manera que puedan plantear } \\
\text { caminos alternativos que trans- } \\
\text { formen la realidad. }\end{array}$ & $\begin{array}{l}\text { Este perfil no aplica para las } \\
\text { categorías de análisis, pues la } \\
\text { Universidad de Medellín hace } \\
\text { énfasis en que sus profesiona- } \\
\text { les tienen la capacidad técni- } \\
\text { ca-científica de desenvolver- } \\
\text { se en entornos económicos y } \\
\text { tecnológicos. En este sentido } \\
\text { no se asevera sobre una for- } \\
\text { mación integral. Sin embargo, } \\
\text { expone que el egresado tendrá } \\
\text { conciencia sobre el impacto } \\
\text { social de su ejercicio profesio- } \\
\text { nal, generando confianza en la } \\
\text { integridad de sus labores, con } \\
\text { lo cualaplica, parcialmente, a } \\
\text { la categoría de análisis de com- } \\
\text { promiso con la sociedad y me- } \\
\text { dio ambiente. }\end{array}$ \\
\hline
\end{tabular}




\begin{tabular}{|c|c|c|}
\hline $\begin{array}{c}\text { IES y/o } \\
\text { Universidad }\end{array}$ & Perfil Profesional & Análisis Categorial \\
\hline $\begin{array}{c}\text { Universidad } \\
\text { EAFIT }\end{array}$ & $\begin{array}{l}\text { El Contador Público egresado } \\
\text { de EAFIT deberá ser un líder } \\
\text { del cambio, abanderado del pro- } \\
\text { ceso del mejoramiento continuo } \\
\text { de los procesos en el interior de } \\
\text { una organización, ya que no es } \\
\text { suficiente la formación de con- } \\
\text { tadores con énfasis en sistemas } \\
\text { contables, financieros, legales } \\
\text { y de costos, que concebidos de } \\
\text { manera aislada de otros subsis- } \\
\text { temas son ineficaces para retro- } \\
\text { alimentar la organización. }\end{array}$ & $\begin{array}{l}\text { Aunque la Universidad EA- } \\
\text { FIT abandere a su profesional } \\
\text { como un líder de cambio, lo } \\
\text { direcciona al campo procesal } \\
\text { de las organizaciones. Por lo } \\
\text { tanto, contiene un alto grado de } \\
\text { énfasis en elementos financie- } \\
\text { ros y normativos que no apli- } \\
\text { can a las categorías de análisis. }\end{array}$ \\
\hline
\end{tabular}

En nuestro programa de Contaduría Pública se forma íntegramente para adquirir tanto los fundamentos y herramientas para gestionar los sistemas de información financiera organizacional, como la conciencia social propia de un bonaventuriano, y que se le exige a quien, como

Universidad de San Buenaventura el contador público, debe dar fe sobre los hechos económicos en contextos regionales y globales. Nuestros egresados se identifican por el notable desarrollo de habilidades personales para la gestión, como el trabajo en equipo, la comunicación asertiva, la solución de conflictos y la cooperación, así como una sinigual vocación de servicio que fomentamos desde los estudiantes.
Se habla sobre un programa que forma a sus estudiantes de manera íntegra para la gestión de los sistemas de información, por lo tanto no cumple con las categorías de análisis. No se identifica de manera concisa el desarrollo de su ejercicio profesional de marera integral o que involucre una conciencia social y/o ambiental.
Universidad Santo Tomás
Programa de Contaduría Pública no vigente en la ciudad de Medellín. 


\section{Contexto usma L y yorms s.}

Tal descripción de los perfiles profesionales resulta de vital importancia para que el estudiante aspirante pueda identificar de manera somera qué puede ofrecerle una IES y/o una universidad en términos del plan de formación. Sin embargo, debe tenerse en cuenta que lo descrito en el perfil profesional de cada programa puede no coincidir con el desarrollo de los contenidos curriculares; respecto de esta aseveración se profundizará más adelante. A continuación se presenta en la Figura 1 la cantidad porcentual de aplicabilidad de los perfiles profesionales en las categorías de análisis.

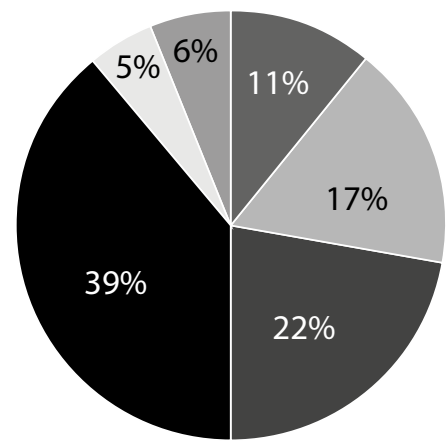

Ciencias sociales

Formación ética y humanística

Responsabilidad social

Compromiso socio-ambiental

Formación integral

No aplica

Figura 1. Aplicabilidad de los perfiles profesionales de los programas de Contaduría Pública en IES y universidades de la ciudad de Medellín a las categorías de análisis.

Elaboración propia (2015).

En los perfiles profesionales de los pregrados de Contaduría Pública analizados, se puede evidenciar que un gran número de IES y universidades no aplican a las categorías de análisis, es decir, que no hacen referencia a especificaciones socio-ambientales, lo cual puede deducirse por la alta mención a los elementos administrativos, financieros, operativos y normativos. Esta tendencia es generada por el auge de la globalización, la cual exige al mundo de hoy elementos generadores de riqueza, en este caso, profesionales operativos que direccionen sus habilidades para el crecimiento de las organizaciones desde un enfoque economicista.

Además, se puede identificar una mención significativa en los perfiles profesionales a la formación integral, de lo cual se puede inferir que las IES y universidades de la ciudad de Medellín en la construcción de sus ideales tuvieron en cuenta el conocimiento como constructo interdisciplinar, es decir, que no se pensó en un principio el programa de Contaduría Pública como 
instrumento técnico-científico sino como una combinación entre lo contable, lo normativo, lo crítico, lo investigativo y lo social. Esto debe ser reconocido, así la realidad de los contenidos académicos no estén en la misma dirección.

Con menor porcentaje de aplicabilidad, se encuentra la categoría de análisis de ciencias sociales, pues sólo una universidad hace énfasis de manera explícita ende su adición a la formación profesional de sus estudiantes. Sin embargo, cabe resaltar que el hecho de considerar importante y fundamental la formación bajo estos elementos, es de gran regocijo, pues, como se abordará más adelante, es el reconocimiento de que se existe como ser y se convive con otros.

\section{De los programas y sus contenidos}

Se consideró pertinente caracterizar los perfiles y los programas de Contaduría Pública de las IES y universidades de la ciudad de Medellín, pues en vista de que la contabilidad no es una disciplina de resultados únicos, genera la necesidad de trabajar de acuerdo con los conocimientos brindados por la interdisciplinariedad. Así pues, a partir de las categorías de análisis previamente enunciadas, se identificaron elementos orientadores respecto del reconocimiento de los espacios socio-ambientales, los cuales están implícitos en las problemáticas que la sociedad hoy presenta.

Por esto, con la finalidad de encontrar sentido y significado a la caracterización, se relacionan los perfiles con los contenidos académicos de cada programa de Contaduría Pública, pues de esta manera se puede identificar la dirección de los contenidos académicos, y con esto, su inferencia en el reconocimiento de los espacios socio-ambientales por parte de los estudiantes que posteriormente serán profesionales.

En primera instancia se consideró a la formación integral como una de las categorías más significativas en los ejes de cada IES y universidad, ésta reúne las otras categorías mencionadas pues "(...)es un concepto íntimamente ligado al sujeto, el hombre y la subjetividad" (Durkheim y Gadamer citados en Quijano, 2006, p.2).

La formación o formación profesional cuando nace es vinculada al trabajo, al saber sobre el trabajo y en general al saber. Saber ser, saber quién ser y saber, definen el campo de problemas de la educación, la formación y la profesión. Educar no puede pensarse sin una formación y sin un saber, es decir, que lo que se diferenciaba y separaba en el capitalismo clásico hoy tiende a integrarse, de tal modo que educar es una acción que lleva a educar el quién ser (sujeto) desde un campo de saber (una profesión) (2006, p.2). 


\section{Contexto usma L y yorms s.}

En ese sentido, la educación debe abrir espacios donde “(...) el futuro profesional elabore proyectos estratégicos de investigación y administración que partan del absoluto respeto de la dignidad humana y del ecosistema" (Rojas, 2006, p.20). Por esa razón se adicionó como categoría de análisis las ciencias sociales, pues resultan pertinentes para la transmisión del saber.

Los intentos destinados a reflexionar sobre la contabilidad social y ambiental se relacionan con nuevos requerimientos que la sociedad demanda a las organizaciones y que se vinculan con su comportamiento social y ambiental (García, 2012, p.212). En este orden de ideas, la formación ética y humanística, y el compromiso socio-ambiental también son categorías que dan vía en los perfiles profesionales y en los programas académicos sobre las perspectivas profesionales que las respaldan.

Finalmente, se identifica como categoría de análisis la responsabilidad social, pertinente en el quehacer profesional contable según los factores contextuales donde las empresas se desarrollan, y por lo tanto, deberían dar cuenta de ello, de manera que la Universidad debe verse involucrada, pues como lo señala Duque et al. "(...) cuestiones como la relación con el entorno internacional y la dinámica económica global, son recurrentes en las propuestas curriculares" (2013, pp.304-305).

Ahora, se dará cuenta de la información encontrada en la Tabla 1, la cual evidencian los datos de las IES y universidades de la ciudad de Medellín con respecto de las categorías de análisis previamente enunciadas.

Las IES y universidades que ofertan el pregrado de Contaduría Pública en la ciudad de Medellín en su mayoría cumplen con las categorías de análisis, pues presentan en la descripción de sus perfiles profesionales varios elementos que dan vía a una educación con miras sociales y ambientales. Aunque cabe anotar que cada programa tiene sus elementos diferenciadores, resulta intrínseca en sus descripciones la certeza de que sus profesionales son capacitados para la solución de problemas en las organizaciones y merecedores de confianza, es decir, se describe algunas características humanas, morales y éticas que la IES y/o universidad afirma formar en el estudiante.

Por ende, esta situación evidencia en los programas académicos pocas asignaturas con énfasis socio-humanísticas y/o ambientales, pues si bien existen asignaturas electivas que permiten dar una mirada interdisciplinar, no es posible identificar con certeza las opciones a elegir por los estudiantes. Así, aunque en los perfiles se evidencie una orientación para que el profesional sea un ser 
integral y responsable con la sociedad que habita, en los programas académicos no se identifica una viabilidad a esas descripciones.

\section{Sobre la investigación y sus líneas}

La investigación permite cuestionar y replantear el conocimiento existente, considerar formas alternativas de hacer, comprender y explicar; por esto es considerada el medio idóneo para lograr la evolución y el perfeccionamiento de cualquier ciencia o disciplina (Sánchez et al. 2013, p.79). Es así que la universidad debe considerar la investigación como pilar fundamental en el desarrollo de sus procesos, ya que ha sido facilitadora del desarrollo permanente del conocimiento.

No obstante, en la práctica educativa de las universidades, las dinámicas de investigación no capturan todavía los intereses de los estudiantes y difícilmente puede evidenciarse sus resultados en términos de formación humana (Muñoz et al., 2015, p.55). Gómez plantea como razón de ello que:

(...) la educación universitaria hoy, pero más aún la educación contable, se enfoca hacia las necesidades de la empresa y de la racionalidad de la misma, lo que impide una verdadera responsabilidad social, tanto de la disciplina y de la profesión, como de los profesionales que las integran (2012, p.74).

A pesar de reconocerse positivamente la iniciativa estatal sobre el fomento de la investigación en las universidades se ha ido tergiversando su propósito general, pues parafraseando a Ospina, sus dinámicas se han visto retrasadas propiamente por la exigencia de rigurosidad metodológica, la cual ha generado para la contabilidad un efecto negativo en la aproximación de sus resultados (2005, p.104).

Aunque en los programas de Contaduría Pública impartidos en la ciudad de Medellín se encuentren pocos contenidos académicos con énfasis en investigación, se intenta caracterizar ahora los progresos académicos e investigativos desde los grupos y semilleros de investigación, que a partir de proyectos de diferentes índoles sobre la disciplina y la sociedad, pueden permitir identificar cuáles tienen como líneas de investigación temas concernientes con el reconocimiento de los espacios socio-ambientales. Los datos sobre éstos se presentan a continuación en la Tabla 2. 
Tabla 2

Grupos, semilleros y líneas de investigación en los programas de Contaduría Pública de las IES y universidades de la ciudad de Medellín

\begin{tabular}{|c|c|c|c|}
\hline $\begin{array}{c}\text { IES y/o } \\
\text { Universidad }\end{array}$ & $\begin{array}{c}\text { Grupo de } \\
\text { Investigación }\end{array}$ & $\begin{array}{c}\text { Línea de } \\
\text { investigación }\end{array}$ & Semilleros \\
\hline \multirow{3}{*}{$\begin{array}{l}\text { Corporación } \\
\text { Universitaria } \\
\text { Adventista }\end{array}$} & \multirow{3}{*}{$\begin{array}{c}\text { Estudios } \\
\text { Organizacionales }\end{array}$} & $\begin{array}{c}\text { Conocimiento, } \\
\text { capacidades y } \\
\text { ventaja competitiva }\end{array}$ & $\begin{array}{c}\text { Gerencia y } \\
\text { Organizaciones }\end{array}$ \\
\hline & & $\begin{array}{c}\text { Finanzas } \\
\text { empresariales }\end{array}$ & \multirow{2}{*}{$\begin{array}{l}\text { Contando lo } \\
\text { Incontable }\end{array}$} \\
\hline & & Marketing & \\
\hline \multirow{2}{*}{$\begin{array}{l}\text { Corporación } \\
\text { Universitaria } \\
\text { Americana }\end{array}$} & \multirow[b]{2}{*}{ GICADE } & \multirow[b]{2}{*}{ Contaduría } & $\begin{array}{c}\text { Camino a las } \\
\text { NIIF }\end{array}$ \\
\hline & & & $\begin{array}{c}\text { Normativa y } \\
\text { tributación social } \\
\text { "Tribuso" }\end{array}$ \\
\hline \multirow{4}{*}{$\begin{array}{l}\text { Corporación } \\
\text { Universitaria } \\
\text { Remington }\end{array}$} & \multirow{4}{*}{ Capital Contable } & Poder y organización & SIMA (Medellín) \\
\hline & & $\begin{array}{l}\text { Contabilidad e } \\
\text { impuestos }\end{array}$ & $\begin{array}{l}\text { Sipyme } \\
\text { (Medellín) }\end{array}$ \\
\hline & & $\begin{array}{l}\text { Fraude corporativo y } \\
\text { delito económico }\end{array}$ & \multirow[b]{2}{*}{ Seincopor } \\
\hline & & $\begin{array}{l}\text { Regulación y normas } \\
\text { internacionales de } \\
\text { contabilidad }\end{array}$ & \\
\hline $\begin{array}{c}\text { Fundación } \\
\text { Escuela } \\
\text { Colombiana De } \\
\text { Mercadotecnia } \\
\text {-Escolme- }\end{array}$ & $\begin{array}{l}\text { GAMES a Grupo } \\
\text { Académico de } \\
\text { Investigación } \\
\text { de Escolme - } \\
\text { GAMES - }\end{array}$ & $\begin{array}{c}\text { Contabilidad, } \\
\text { Finanzas y Contexto } \\
\text { Social }\end{array}$ & $\begin{array}{l}\text { Semillero } \\
\text { Contable }\end{array}$ \\
\hline $\begin{array}{l}\text { Universidad } \\
\text { Católica } \\
\text { Luis Amigó }\end{array}$ & CONTAS & $\begin{array}{c}\text { Contabilidad social y } \\
\text { ambiental }\end{array}$ & CINESCA \\
\hline
\end{tabular}




\begin{tabular}{|c|c|c|c|}
\hline $\begin{array}{c}\text { IES y/o } \\
\text { Universidad }\end{array}$ & $\begin{array}{c}\text { Grupo de } \\
\text { Investigación }\end{array}$ & $\begin{array}{c}\text { Línea de } \\
\text { investigación }\end{array}$ & Semilleros \\
\hline \multirow{3}{*}{$\begin{array}{l}\text { Fundación } \\
\text { Universitaria } \\
\text { María Cano }\end{array}$} & \multirow{3}{*}{$\begin{array}{c}\text { Grupo de } \\
\text { investigación } \\
\text { SUMAR. }\end{array}$} & Emprendimiento & \\
\hline & & Gerencia & \\
\hline & & $\begin{array}{c}\text { Entorno y } \\
\text { Competitividad }\end{array}$ & \\
\hline \multirow{5}{*}{$\begin{array}{c}\text { Institución } \\
\text { Universitaria } \\
\text { Salazar y Herrera }\end{array}$} & \multirow{5}{*}{ GIRE } & $\begin{array}{l}\text { Planeación } \\
\text { estratégica }\end{array}$ & \multirow{3}{*}{ GENIOS } \\
\hline & & $\begin{array}{l}\text { Marketing } \\
\text { estratégico }\end{array}$ & \\
\hline & & Estrategias globales & \\
\hline & & $\begin{array}{c}\text { Estrategias } \\
\text { organizacionales } \\
\text { contemporáneas }\end{array}$ & \multirow[t]{2}{*}{ GIIAMOS } \\
\hline & & Finanzas estratégicas & \\
\hline \multirow{5}{*}{$\begin{array}{c}\text { Politécnico } \\
\text { Colombiano } \\
\text { Jaime Isaza } \\
\text { Cadavid }\end{array}$} & \multirow{5}{*}{ LIKAPAAY } & $\begin{array}{c}\text { Control, Información } \\
\text { y Estado }\end{array}$ & \multirow{5}{*}{$\begin{array}{c}\text { CIRAK } \\
\text { Investigación } \\
\text { Contable }\end{array}$} \\
\hline & & $\begin{array}{c}\text { Control, Información } \\
\text { y Ambiente }\end{array}$ & \\
\hline & & $\begin{array}{c}\text { Control, Información } \\
\text { y Gestión }\end{array}$ & \\
\hline & & $\begin{array}{c}\text { Control, Información } \\
\text { y Pedagogía }\end{array}$ & \\
\hline & & Teoría Contable & \\
\hline
\end{tabular}




\begin{tabular}{|c|c|c|c|}
\hline $\begin{array}{c}\text { IES y/o } \\
\text { Universidad }\end{array}$ & $\begin{array}{c}\text { Grupo de } \\
\text { Investigación }\end{array}$ & $\begin{array}{c}\text { Línea de } \\
\text { investigación }\end{array}$ & Semilleros \\
\hline \multirow{3}{*}{$\begin{array}{c}\text { Tecnológico de } \\
\text { Antioquia }\end{array}$} & \multirow{3}{*}{$\begin{array}{l}\text { Observatorio } \\
\text { Público }\end{array}$} & $\begin{array}{l}\text { Contabilidad con } \\
\text { carácter disciplinar }\end{array}$ & \multirow{3}{*}{ CONTAME } \\
\hline & & $\begin{array}{c}\text { Políticas Públicas, } \\
\text { Gobierno y } \\
\text { Planeación }\end{array}$ & \\
\hline & & $\begin{array}{c}\text { Métodos } \\
\text { y Metodologías } \\
\text { de Investigación } \\
\text { Aplicada }\end{array}$ & \\
\hline \multirow{3}{*}{$\begin{array}{l}\text { Universidad } \\
\text { Autónoma } \\
\text { Latinoamericana } \\
\text {-Unaula- }\end{array}$} & \multirow{3}{*}{ GICOR } & $\begin{array}{l}\text { Fundamentación } \\
\text { teórica y } \\
\text { epistemológica de } \\
\text { la Contabilidad } \\
\text { y de los estudios } \\
\text { organizacionales }\end{array}$ & \multirow{3}{*}{ LEXEMA } \\
\hline & & $\begin{array}{c}\text { Desarrollos } \\
\text { tecnológicos en } \\
\text { Contabilidad y su } \\
\text { aplicación al ámbito } \\
\text { de las organizaciones }\end{array}$ & \\
\hline & & Educación contable & \\
\hline \multirow{4}{*}{$\begin{array}{c}\text { Universidad } \\
\text { Cooperativa de } \\
\text { Colombia }\end{array}$} & \multirow{4}{*}{ GIPC } & $\begin{array}{c}\text { Contabilidad y } \\
\text { Finanzas } \\
\end{array}$ & \multirow{4}{*}{ VINCO } \\
\hline & & Control y Auditoria & \\
\hline & & $\begin{array}{c}\text { Tributaria y } \\
\text { Hacienda Pública }\end{array}$ & \\
\hline & & $\begin{array}{c}\text { Economía Solidaria } \\
\text { y Desarrollo } \\
\text { Regional }\end{array}$ & \\
\hline
\end{tabular}

Grupo de

Unvestigaciones
Antioquia

contables -

Semillero de

tributaria

GICCO UdeA 


\begin{tabular}{|c|c|c|c|}
\hline $\begin{array}{c}\text { IES y/o } \\
\text { Universidad }\end{array}$ & $\begin{array}{c}\text { Grupo de } \\
\text { Investigación }\end{array}$ & $\begin{array}{c}\text { Línea de } \\
\text { investigación }\end{array}$ & Semilleros \\
\hline \multirow{3}{*}{$\begin{array}{l}\text { Universidad de } \\
\text { Medellín }\end{array}$} & \multirow{3}{*}{$\begin{array}{c}\text { Grupo de } \\
\text { investigaciones } \\
\text { contables y gestión } \\
\text { pública. }\end{array}$} & $\begin{array}{l}\text { Gestión de la } \\
\text { información contable }\end{array}$ & \\
\hline & & $\begin{array}{c}\text { Gestión financiera } \\
\text { corportativa }\end{array}$ & \\
\hline & & $\begin{array}{l}\text { Legislación y } \\
\text { práctica tributaria }\end{array}$ & \\
\hline \multirow{5}{*}{$\begin{array}{l}\text { Universidad } \\
\text { EAFIT }\end{array}$} & \multirow{5}{*}{$\begin{array}{l}\text { Información y } \\
\text { Gestión }\end{array}$} & $\begin{array}{l}\text { Emprendimiento y } \\
\text { gestión }\end{array}$ & $\begin{array}{c}\text { Semillero de } \\
\text { investigación de } \\
\text { control, auditoría } \\
\text { y riesgos (Sicar) }\end{array}$ \\
\hline & & $\begin{array}{c}\text { Control, auditoría y } \\
\text { riesgos }\end{array}$ & $\begin{array}{c}\text { Semillero } \\
\text { Eafitense de } \\
\text { Investigación } \\
\text { Contable (Seic) }\end{array}$ \\
\hline & & $\begin{array}{l}\text { Contabilidad y } \\
\text { finanzas }\end{array}$ & $\begin{array}{c}\text { Semillero de } \\
\text { Investigación } \\
\text { Tributaria (SIT) }\end{array}$ \\
\hline & & $\begin{array}{c}\text { Costos estrátegicos y } \\
\text { presupuestos }\end{array}$ & \multirow{2}{*}{$\begin{array}{c}\text { Semillero de } \\
\text { investigación } \\
\text { en contabilidad } \\
\text { de costos y } \\
\text { gerencial (Sinco) }\end{array}$} \\
\hline & & $\begin{array}{c}\text { Legislación } \\
\text { tributaria, laboral y } \\
\text { comercial }\end{array}$ & \\
\hline \multirow{3}{*}{$\begin{array}{c}\text { Universidad } \\
\text { de San } \\
\text { Buenaventura }\end{array}$} & \multirow{3}{*}{ GRICE } & Control & \multirow{3}{*}{ EXCON } \\
\hline & & $\begin{array}{l}\text { Negociación } \\
\text { y relaciones } \\
\text { internacionales }\end{array}$ & \\
\hline & & $\begin{array}{l}\text { Pensamiento } \\
\text { administrativo }\end{array}$ & \\
\hline
\end{tabular}

Elaboración propia, 2015. 


\section{Conterto usma L y yomess s.}

La profesión contable sufre una estigmatización que la caracteriza como utilitarista o instrumentalista y mecanicista que a los ojos del común la reduce a un campo de acción netamente técnico y normativo. Sin embargo, dentro del proceso de educación y formación de los contables, más específicamente dentro de los programas de estudio, se evidencian asignaturas tales como teoría contable, teoría de la investigación o investigación contable que dan vía a que el estudiante pueda explorar e integrar aspectos que son aplicables a nivel personal y profesional. La investigación se da en ámbitos curriculares y extracurriculares, sin embargo, para efectos de éste acápite se hace referencia a aquellos grupos y líneas de investigación que se enmarcan dentro de lo institucional y que han sido previamente enunciadas en la Tabla 2.

Teniendo en cuenta la información preliminar, es posible establecer que los enfoques generales y/o específicos de las líneas de investigación son diversificados, pues abarcan temáticas concernientes a problemáticas y aspectos financieros, organizacionales, económicos $\mathrm{u}$ otros aspectos normativos $\mathrm{y}$ técnicos como también tópicos referentes al desarrollo social y disciplinar. Sin embargo, es pertinente denotar que en la inclinación temática de la mayoría de las líneas de investigación priman los aspectos referentes a las finanzas, desarrollo económico, impositivo y empresarial. Así pues, es preocupante ver cómo los procesos investigativos que se gestan al interior de las comunidades educativas se encaminan en pro de la producción de información útil para las organizaciones y no con el fin de formar un individuo más consciente de otras realidades que no tengan que ver necesariamente con las anteriormente descritas sino aquellas que se refieran a problemáticas sociales, culturales y educativas.

Es importante aclarar que las problemáticas por las que deben preocuparse las líneas de investigación no son excluyentes, pues el desarrollo de temas financieros y económicos también son menesteres dentro del proceso profesional y académico de los estudiantes. Sin embargo, son las temáticas de carácter social y ambiental las que permiten que el individuo se conciba a sí mismo como un sujeto analítico y transformador de estas realidades tal como se describe en acápites anteriores. Razón de esto dan los profesores Muñoz, Ruiz y Sarmiento cuando manifiestan que:

(...) lo social como escenario y fenómeno vinculante del sujeto se totaliza en el trabajo, el cual se convierte en la expresión del mundo de la vida, de lo cotidiano en el estudiante. Podría pensarse que la academia actúa como un agente mediador entre el mundo del trabajo y la vida cotidiana de los estudiantes; pero ésta se ocupa más de ofrecer respuestas a los problemas del mundo empresarial, en tanto es el medio que las exige, sin estímulo al pensamiento que dé respuestas a los 
problemas de lo cotidiano o lo que escape al mundo del trabajo, por cuanto sus preguntas específicas no son visibles a los ojos de lo académico (2015, p.77).

Los grupos de investigación y demás procesos investigativos que surgen en el interior de los devenires académicos y formativos de los estudiantes, pueden representar para aquellos que los integran la oportunidad de trascender más allá de los contenidos de los programas de estudio suscitando en ellos el deseo de conocimiento y además lograr su conexión e identificación con las realidades sociales y ambientales. Y es allí, en ese interés, en donde nace el sujeto que a través de su experiencia en la educación superior se apropia de su rol en pro del reconocimiento, reconciliación y beneficio de los espacios socio-ambientales.

\section{Los estudiantes y su aporte académico en la discusión socio-ambiental}

En este último acápite se pretende esbozar un análisis sobre el aporte académico de los estudiantes de Contaduría Pública a la discusión socioambiental. Para ello, se plantea un contexto que permita comprender el entorno en el cual los procesos educativos y formativos se han desarrollado, y también, un análisis de los sentires y pensares de los estudiantes de Contaduría Pública, es decir, identificar la incidencia en la discusión socioambiental desde la experiencia de algunos estudiantes respecto de este objetivo por medio de una encuesta aplicada.

La humanidad actualmente enfrenta un desafío decisivo en torno a su supervivencia, encontrar una opción de consumo de recursos naturales, renovables y no renovables, que permita la existencia de las sociedades modernas presentes y sus futuras generaciones (Amaya y Malaver, 2015, p.118). Lo cual ha evidenciado, en resumen, un desinterés en el cuidado de la naturaleza y, a su vez, un interés por el dominio de sus atributos sin importar la relación hombrenaturaleza, que según el profesor Rincón (...) abarca mucho más que la simple interacción de consumo y el despliegue de las acciones humanas (2007, p.4).

Además de dicho desconocimiento, el desmesurado aprovechamiento sobre el territorio y la carencia del fomento de buenas relaciones entre las personas que lo ocupan son consecuencias de la potestad que no le corresponde al hombre sobre el mundo.

Es responsabilidad de la humanidad resarcir su abuso y reconciliarse con el espacio que le ha permitido desarrollarse, y darle paso a una toma de conciencia que posibilite el surgimiento de buenas prácticas sociales y ambientales. 


\section{Contexto usma L y yorms s.}

Cuando el individuo comprenda su responsabilidad inherente será el artífice de esta transformación, pues "(...) se tiene la certeza de que el ser humano es capaz de solucionar a través de sus actos los problemas sociales que existen debido, precisamente, a sus acciones" (Ramiro, 2005, p.101).

Sin duda el ser humano puede ser artífice de transformaciones sociales, las cuales pueden verse materializadas a partir de la concienciación del ser, pues "es propio de la conciencia crítica su integración con la realidad" (Freire, 1965). De esta manera es que se pueda tomar como aspecto fundamental en la concienciación del ser la educación, pues ésta y “(...) las prácticas sociales y culturales, se articulan bajo la égida del signo y el simulacro, de manera que esta hibridación se convierte por excelencia en una maquinaria poderosa de producción de sentido, modificando radicalmente la percepción del mundo" (Martínez, 2008, p.15).

Sin embargo, como respuesta a lógicas conductuales, el individuo busca reconocimiento del éxito, estabilidad económica y calidad de vida, razón por la cual decide aproximarse a la educación por medio de la universidad, ente que respalda formalmente conocimientos, y que puede llegar a garantizar la superación personal y profesional del sujeto. A pesar de esta realidad, desde un punto de vista ideológico, la universidad representa el epicentro para el cultivo del conocimiento, ya que se le "(...) ha otorgado la responsabilidad de ser la conciencia crítica de la sociedad, es decir, que paralelamente a la enseñanza de los diferentes saberes debe buscar influir positivamente en la solución de los problemas que en la sociedad se presentan" (Sánchez, 2013, p.80).

Aunque se le ha otorgado tal responsabilidad a la universidad, también es adecuado creer que el estudiante tiene participación de la responsabilidad influyendo positivamente en la solución de problemas, y por ende, puede desempeñar un rol significativo en su formación. Así pues, resulta primordial que el estudiante se conciba a sí mismo como un agente transformador, el cual debe trascender los contenidos académicos.

Sin embargo, es imperativo reconocer que aunque existan inconformidades respecto de las dinámicas de la educación contable, como se ha expresado en el presente trabajo, se han evidenciado aportes y avances por parte de algunos estudiantes de Contaduría Pública en Colombia, por ejemplo, a partir de los espacios de reflexión y debate que ha generado la Federación Nacional de Estudiantes de Contaduría Pública de Colombia -FENECOP-. Se reconocen esfuerzos realizados por parte de algunos autores, en este caso en materia de educación contable y enel reconocimiento de los espacios socio-ambientales; 
los conocimientos acumulados sobre el tema a abordar facilitan por medio de un rastreo dar cuenta de sus antecedentes investigativos.

Por esta razón, se buscó identificar en el contexto histórico la correlación que existe entre el objetivo de este trabajo y la producción académica publicada en los libros de ponencias de los Congresos de Estudiantes de Contaduría Pública de Colombia -FENECOP- entre los años 1993-2014. A continuación, se presentala Tabla 4 con la información anterior, donde la categoría de análisis es el reconocimiento de los espacios socio-ambientales en los programas de Contaduría Pública en Colombia. Dicha categoría de análisis puede reducirse en la mera existencia de un escrito que haga referencia a tópicos como educación contable, contabilidad ambiental, contabilidad social.

Tabla 3

Ponencias que tienen relación con el reconocimiento de los espacios socioambientales en los programas de Contaduría Pública publicadas en los Congresos de FENECOP

$\begin{array}{cccc}\mathrm{N}^{\mathrm{o}} \mathrm{y} & \text { Nombre de la } & & \\ \text { año de } & \text { Ponencia } & \text { Autores } & \text { Comisión } \\ \text { Congreso } & & & \end{array}$

\begin{tabular}{|c|c|c|c|c|}
\hline VIII-1993 & $\begin{array}{l}\text { La dimensión } \\
\text { medio } \\
\text { ambiental en } \\
\text { la Contaduría } \\
\text { Pública }\end{array}$ & $\begin{array}{c}\text { Olver } \\
\text { Quijano } \\
\text { Valencia }\end{array}$ & Social & $\begin{array}{l}\text { Este autor aborda la dis- } \\
\text { tinción entre sociedad y } \\
\text { naturaleza, y a su vez, el } \\
\text { papel de la Contaduría } \\
\text { Pública en su reconoci- } \\
\text { miento, pretende detec- } \\
\text { tar posibles líneas de in- } \\
\text { vestigación. No aborda } \\
\text { la categoría de análisis }\end{array}$ \\
\hline \multirow{3}{*}{ IX-1995 } & \multirow{3}{*}{$\begin{array}{l}\text { A propósito } \\
\text { de la reflexión } \\
\text { ecología- } \\
\text { contabilidad }\end{array}$} & $\begin{array}{c}\text { William } \\
\text { Rojas }\end{array}$ & \multirow{3}{*}{ Social } & \multirow{3}{*}{$\begin{array}{l}\text { Este texto devela una } \\
\text { preocupación hacia la } \\
\text { contaminación ambien- } \\
\text { tal. Propone la ecología } \\
\text { como alternativa para la } \\
\text { recomposición social. } \\
\text { No aborda la categoría } \\
\text { de análisis. }\end{array}$} \\
\hline & & $\begin{array}{l}\text { Claudia } \\
\text { Ceballos }\end{array}$ & & \\
\hline & & $\begin{array}{l}\text { Hernán } \\
\text { Caicedo }\end{array}$ & & \\
\hline
\end{tabular}




\begin{tabular}{|c|c|c|c|c|}
\hline $\begin{array}{c}\mathrm{N}^{\mathrm{o}} \mathrm{y} \\
\text { año de } \\
\text { Congreso }\end{array}$ & $\begin{array}{l}\text { Nombre de la } \\
\text { Ponencia }\end{array}$ & Autores & Comisión & Análisis \\
\hline X-1996 & $\begin{array}{l}\text { En busca de } \\
\text { la Contaduría } \\
\text { Pública }\end{array}$ & $\begin{array}{c}\text { Yenny } \\
\text { Patricia } \\
\text { Quintero B. }\end{array}$ & Educativa & $\begin{array}{l}\text { Este autor realiza un es- } \\
\text { tado del arte acerca de } \\
\text { la educación, la univer- } \\
\text { sidad y el currículum. } \\
\text { Define la estructura } \\
\text { curricular de algunas } \\
\text { universidades. Propone } \\
\text { la creación de nuevos } \\
\text { métodos pedagógicos. } \\
\text { No aborda la categoría } \\
\text { de análisis. }\end{array}$ \\
\hline X-1996 & $\begin{array}{l}\text { El Contador } \\
\text { Público: } \mathrm{Su} \\
\text { nivel, su } \\
\text { responsabilidad } \\
\text { y su proyección } \\
\text { social- } \\
\text { ecológica }\end{array}$ & $\begin{array}{l}\text { Orlando } \\
\text { Vargas } \\
\text { Martínez }\end{array}$ & Social & $\begin{array}{l}\text { Esta ponencia realiza } \\
\text { una interrelación entre la } \\
\text { realidad social y la reali- } \\
\text { dad ambiental. Hace un } \\
\text { análisis de la formación } \\
\text { contable desde la óptica } \\
\text { ecológica. No aborda la } \\
\text { categoría de análisis. }\end{array}$ \\
\hline XI-1997 & $\begin{array}{l}\text { La educación } \\
\text { frente al } \\
\text { desarrollo } \\
\text { sostenible }\end{array}$ & $\begin{array}{c}\text { Liliana } \\
\text { Velásquez } \\
\text { Orozco }\end{array}$ & Educativa & $\begin{array}{l}\text { Este escrito devela que } \\
\text { su principal preocupa- } \\
\text { ción son las políticas so- } \\
\text { ciales del conocimiento } \\
\text { que imparte la univer- } \\
\text { sidad. Pretende hacer } \\
\text { una concientización } \\
\text { respecto de la necesidad } \\
\text { de nuevos mecanismos } \\
\text { pedagógicos. No aborda } \\
\text { la categoría de análisis. }\end{array}$ \\
\hline XII-1998 & $\begin{array}{l}\text { A propósito de } \\
\text { la educación } \\
\text { ambiental en } \\
\text { la formación } \\
\text { integral del } \\
\text { Contador } \\
\text { Público }\end{array}$ & $\begin{array}{c}\text { Juan Carlos } \\
\text { Cuervo } \\
\text { Fernández }\end{array}$ & Social & $\begin{array}{l}\text { Este autor plantea que } \\
\text { se debe reivindicar la } \\
\text { educación ambiental } \\
\text { como una propuesta } \\
\text { válida en la formación } \\
\text { del Contador Público. } \\
\text { No aborda la categoría } \\
\text { de análisis. }\end{array}$ \\
\hline
\end{tabular}




\begin{tabular}{|c|c|c|c|c|}
\hline $\begin{array}{c}\mathrm{N}^{\mathrm{o}} \mathrm{y} \\
\text { año de } \\
\text { Congreso }\end{array}$ & $\begin{array}{c}\text { Nombre de la } \\
\text { Ponencia }\end{array}$ & Autores & Comisión & Análisis \\
\hline $\begin{array}{l}\text { XVII- } \\
2003\end{array}$ & $\begin{array}{l}\text { Elementos } \\
\text { conceptuales } \\
\text { para una } \\
\text { propuesta } \\
\text { pedagógica en } \\
\text { la formación } \\
\text { ética del } \\
\text { estudiante de } \\
\text { Contaduría } \\
\text { Pública }\end{array}$ & $\begin{array}{l}\text { Julián } \\
\text { Andrés } \\
\text { Gómez } \\
\text { Sánchez }\end{array}$ & Educativa & $\begin{array}{l}\text { Aunque esta ponencia } \\
\text { es acorde según la ma- } \\
\text { nera como retoma las } \\
\text { problemáticas actuales } \\
\text { en la formación del es- } \\
\text { tudiante de Contaduría } \\
\text { Pública y sugiere ele- } \\
\text { mentos para una reno- } \\
\text { vación en los programas } \\
\text { educativos. No aborda } \\
\text { la categoría de análisis. }\end{array}$ \\
\hline XIX-2007 & $\begin{array}{l}\text { El énfasis de } \\
\text { lo disciplinar } \\
\text { sobre lo } \\
\text { profesional } \\
\text { para la } \\
\text { formación } \\
\text { del Contador } \\
\text { Público: una } \\
\text { experiencia } \\
\text { en formación } \\
\text { contable }\end{array}$ & $\begin{array}{c}\text { Sergio Luis } \\
\text { Ordóñez } \\
\text { Noreña }\end{array}$ & $\begin{array}{c}\text { Mesa de } \\
\text { Trabajo } \\
\mathrm{N}^{\circ} 1\end{array}$ & $\begin{array}{l}\text { Este autor realiza un lla- } \\
\text { mado a la universidad } \\
\text { para que en la forma- } \\
\text { ción del estudiante de } \\
\text { Contaduría Pública no } \\
\text { sólo se enseñe la técnica } \\
\text { contable sino también } \\
\text { su trasfondo económi- } \\
\text { co, social y humano. } \\
\text { Este texto no aborda la } \\
\text { categoría de análisis. }\end{array}$ \\
\hline XXI-2009 & $\begin{array}{c}\text { La } \\
\text { responsabilidad } \\
\text { social del } \\
\text { Contador } \\
\text { Público: Un rol } \\
\text { necesario para } \\
\text { la construcción } \\
\text { de una ética } \\
\text { capitalista }\end{array}$ & $\begin{array}{c}\text { José Julio } \\
\text { Vergara } \\
\text { Arrieta }\end{array}$ & Social & $\begin{array}{l}\text { Este autor expone como } \\
\text { eje central de su ponen- } \\
\text { cia: la responsabilidad } \\
\text { social, aunque hace un } \\
\text { llamado a la comunidad } \\
\text { contable para que par- } \\
\text { ticipe en la transforma- } \\
\text { ción de la sociedad, no } \\
\text { aborda específicamente } \\
\text { elementos ambientales } \\
\text { o la educación contable. }\end{array}$ \\
\hline
\end{tabular}




\begin{tabular}{|c|c|c|c|c|}
\hline $\begin{array}{c}\mathrm{N}^{\mathrm{o}} \mathrm{y} \\
\text { año de } \\
\text { Congreso }\end{array}$ & $\begin{array}{l}\text { Nombre de la } \\
\text { Ponencia }\end{array}$ & Autores & Comisión & Análisis \\
\hline XXI-2009 & $\begin{array}{c}\text { Características } \\
\text { del currículum } \\
\text { en la educación } \\
\text { profesional de } \\
\text { la Contaduría } \\
\text { Pública }\end{array}$ & $\begin{array}{l}\text { William } \\
\text { Andrés } \\
\text { Polo Díaz }\end{array}$ & Educativa & $\begin{array}{l}\text { La tesis central de esta } \\
\text { ponencia está enfoca- } \\
\text { da en las problemáticas } \\
\text { que acogen los pro- } \\
\text { gramas de Contaduría } \\
\text { Pública colombianos, } \\
\text { está muy acorde con lo } \\
\text { que abarca el presente } \\
\text { trabajo, pues expone } \\
\text { una propuesta orienta- } \\
\text { da al reconocimiento de } \\
\text { asignaturas con énfasis } \\
\text { social, sin embargo, no } \\
\text { hace énfasis en el as- } \\
\text { pecto ambiental, por lo } \\
\text { tanto, no aborda la cate- } \\
\text { goría de análisis. }\end{array}$ \\
\hline
\end{tabular}

Elaboración propia, 2015.

Las anteriores ponencias, enunciadas en la Tabla 3, abordan problemáticas cercanas como educación, conciencia ambiental, desarrollo sostenible y contabilidad social, propuestas que han enriquecido la reflexión sobre de los programas de Contaduría Pública, lo cual es valioso para la construcción de referentes teóricos y contextuales respecto de este trabajo.

\section{Respecto de los sentires y pensares: a propósito de la triangulación de la información}

En tanto, identificar y analizar la percepción, los sentires y pensares de los estudiantes sobre la discusión socio-ambiental y su formación profesional, se determinó como población a los estudiantes de Contaduría Pública de la ciudad de Medellín, y como muestra o unidad de análisis a algunos estudiantes de últimos semestres, cuyo criterio de selección se determinó por su pertenencia a un grupo, semillero o colectivo de investigación siendo partícipes de espacios que contribuyen -de manera explícita o implícita- a la discusión sobre el reconocimiento de los espacios socio-ambientales, en tanto se permiten a sí mismos abordar problemáticas que la mayoría de los casos son ajenas a las aulas de clase. 
Con el fin de contextualizar y conceptualizar los resultados de la entrevista estructurada, se iniciará por agrupar las definiciones de espacio socioambiental. Se puede concluir, a través de la consolidación de las respuestas de los estudiantes de Contaduría Pública, que su concepto y/o definición de espacio socio-ambiental coincide en que es un campo o un lugar físico en el cual se enmarca la confluencia de los factores humanos y no humanos. Lo cual demuestra que la mayoría reconocen la existencia de otros elementos físicos y naturales en el entorno que habitan, concepción que se acerca a la optada por este trabajo. Sin embargo, se puede identificar que los estudiantes no hacen mención al papel del individuo en dicho espacio, lo que evidencia la falta de responsabilidad con el otro y su entorno.

A su vez, al consolidar las respuestas de los estudiantes sobre cuál consideraban que era su rol en la educación contable, la mayoría de ellos hizo énfasis en que este rol debía ser el de individuos responsables de ejecutar una transformación, pero que esta suposición ideal no se veía reflejada en la actualidad. Situación que puede explicarse por la suposición de esas acciones, pues ésta, se llegan a considerar siempre como una opción y por ende, se atiene a la iniciativa propia del estudiante y se espera un incentivo por parte del plan de estudios. Así que los estudiantes no van más allá de la educación impartida por la institucionalidad y responsabilizan a la academia en su totalidad por su falta de fuerza en las transformaciones sociales.

Sin embargo, y aunque la primacía de los contenidos académicos sea financiera e instrumentalista, los estudiantes se han interesado por temas y problemáticas que viven a diario en su proceso formativo como Contadores Públicos, y así no se evidencie una tendencia en temas ambientales, se puede inferir aspectos provechosos en la discusión socio-ambiental.

(...) como futuros profesionales tenemos la posibilidad de optar por un rol transformador en cuento a educación y formación contable respecta, pues la inconformidad con las dinámicas educativas actuales debería ser el mayor incentivo para participar en la estructuración de un modelo educativo a la medida de nuestras necesidades, y por qué no, de nuestros sueños como ciudadanos (estudiante entrevistado). ${ }^{2}$

En este sentido, y refiriéndose explícitamente al programa académico que es el eje central de este trabajo, hubo respuestas diversificadas respecto del enfoque del mismo, sin embargo, la mayoría de estudiantes encuestados manifestaron

2 Entrevista concedida a las autoras con registro digital. 


\section{Contexto usma L y yorms s.}

que el enfoque de los programas podían definirse como Financiero, y TénicoNormativo. Lo que permite ratificar lo expuesto en acápites anteriores sobre la necesidad de que los planes de estudio contengan contenidos tanto financieros, técnico-normativos como socio-humanísticos, éticos y ambientales.

Aunque los perfiles profesionales y los planes de estudio contengan asignaturas que sugieren contenidos socio-ambientales, no evidencian realmente su enfoque. Lo cual responsabiliza a las instituciones y universidades a pensar y repensar sus planes académicos, pero no en vía de añadir más asignaturas sino de mejorar los contenidos académicos de las ya existentes.

Finalmente, a partir del análisis de los sentires y pensares compartidos por los estudiantes se puede establecer que, durante sus experiencias académicas consideran que la institución y/o universidad en la cual se desarrolla su proceso formativo debe contribuir más significativamente, desde la pedagogía, la metodología y la investigación, para que se propicie un avance en los procesos formativos y, además, se constituya una conciencia crítica que direccione un reconocimiento de sí mismos como artífices de realidades y partícipes del cambio.

\section{Conclusiones}

El sentido del reconocimiento de los espacios socio-ambientales requiere por parte del individuo un reconocimiento propio. Su desarrollo resulta interrelacionado en aquellos ámbitos territoriales y simbólicos, lo cual, más allá de comprometer la contabilidad, compromete una conciencia humana y con ella la comprensión de que su desarrollo vital está ligado directamente con la preservación del mundo. En esa medida, es necesario propender e involucrar, como estudiante o profesional, el ejercicio contable conjugado con un accionar social adicional, el cual puede ser influenciado desde la educación.

En esa medida, por ejemplo, desde los perfiles profesionales y los contenidos académicos de los programas de Contaduría Pública, se puede dilucidar la vinculación de contenidos socio-ambientales en los planes de formación, pues las IES y universidades tienen como responsabilidad educar y formar individuos responsables y sensibles, pero sobre todo ciudadanos íntegros y conscientes de los espacios en los que habita. Por lo tanto, debe fomentar en el estudiante no sólo un deseo de aprender, sino de emplear sus conocimientos en la medida que genere un impacto positivo en el espacio socio-ambiental que habitan, pero éste resulta ser un aspecto todavía por complementar. 
La investigación, por su lado, se puede ver enmarcada desde los grupos, semilleros y líneas como una alternativa que trasciende los contenidos académicos de los programas, los cuales van desde temas de carácter financiero, social, ambiental y hasta cultural. De allí que los grupos de investigación posean libertad en escoger sus líneas de trabajo, sin embargo, en este texto se logra reconocer una inclinación temática referente a las finanzas, normatividad y desarrollo organizacional. Por lo tanto, la investigación aún debe ser acercada a temas de carácter social y ambiental, incentivando así al pensamiento crítico y consciente de resultados investigativos que puedan replantear el conocimiento tradicional.

El aporte académico estudiantil a la discusión socio-ambiental se remonta, hace años, hacia el interés por temas sociales, educativos y/o disciplinares, y que, con sorpresa, no ha cambiado en la actualidad. De ahí que el papel de los escenarios educativos siga siendo una discusión inacabada, pues según la encuesta los estudiantes manifiestan una inconformidad con sus planes de formación. El estudiante del programa de Contaduría Pública de la ciudad de Medellín, debería manifestar en su rol de individuo transformador su inconformidad respecto a los contenidos académicos de su institución y/o universidad, ya que resulta inconveniente esperar a que éstas contribuyan desde otros enfoques en su desarrollo profesional. Por esta razón, es provechoso invitar a los estudiantes contables para que reconozcan y se hagan responsables de su rol como eje central de transformación y ejecución; que trasciendan de sus labores operativas; que se permitan a sí mismos comprender y respetar el entorno vital, o sea el medio ambiente, a través de su profesión, en vista de que puédelo cual puede considerarse como un primer paso en la obtención de la formación que sueñan.

\section{Referencias}

Aguilar, P., Ceballos, A., Andrade, L. y Gómez, Y. (2015). La educación contable universitaria: herramientas formativas para satisfacer las necesidades de las organizaciones, el Estado, la comunidad y las familias. En-Contexto, 3, 161-180.

Amaya, Y. y Malaver, S. (2015). Repensando el papel de la huella ecológica en el campo de la ecología política. Amazonía en disputa. Reflexiones desde la disciplina contable. Ponencias XXVI Congreso Nacional de Estudiantes de Contaduría Pública de Colombia. Florencia: Cecam/ Fenecop.

Beltrán, L. (1995). Variables e indicadores ambientales. Santa fé de Bogotá: Universidad de los Andes. 


\section{Contexto usma L y yoms s}

Bourdieu, P. (1985). Espacio social y campo político. Recuperado de https://es.scribd.com/doc/73345896/Bourdieu-Textos-Espacio-SocialPosiciones-Campos

Claval, P. (2002). El enfoque cultural y las concepciones geográficas del espacio. Boletín de la asociación de geógrafos españoles. 34, 21-39.

Duque, D., Obando, D., Muñoz, L., López, C. y Cañas, S. (2013). Formación de Contadores Públicos en Colombia: Una revisión de contenido y contexto. Teuken Bidikay, 4, 281-304.

Freire, P. (1965). La educación como práctica de libertad. Recuperado de http://www.educacionsalta.com.ar/files/archivos/bibliotecas/3/ eccbc87e4b5ce2fe28308fd9f2a7baf3.pdf

Galeano, E. (2004). Patas arriba. La escuela del mundo al revés. Ciudad de México, México: Siglo XXI Editores.

Gallón, N. (2013). La formación ciudadana en el Contador Público: Una apuesta ineludible desde la educación filosófica y democrática. Letras de Tinta Sangre. Razones y pasiones en la nueva investigación contable. Ponencias XIV Congreso Nacional de Estudiantes de Contaduría Pública de Colombia. Medellín: Yupana/Fenecop.

García, I. (2012). Problemas de la Contabilidad social y ambiental: Algunas reflexiones sobre la necesidad de un abordaje interdisciplinario. Contaduría Universidad de Antioquia, 60, 209-218.

Gómez, Y. (2013). Enseñabilidad y educabilidad. Nuevas tendencias en la enseñanza y la investigación contables. En Contexto, 2, 179-192.

Gómez, Y. (2012). Pensar y renovar los modelos de educación contable: Una discusión pendiente. Teuken Bidikay, 3, 59-74.

Martínez, G. (2007). La educación contable en el nuevo contexto de significación. Contaduría Universidad de Antioquia, 50, 43-76.

Martínez, G. (2008). Los desafíos en la educación contable: "encrucijada de una formación monodisciplinaria en un entorno complejo e incierto". PorikAn, 11, 13-72.

Muñoz, S., Ruiz, G. y Sarmiento, H. (2015). Didácticas para la formación en investigación contable: una discusión crítica de las prácticas de enseñanza. Revista Facultad de Ciencias Económicas: Investigación y Reflexión, 23(1) 53-86. 
Quijano, O. (2006). En mi juventud interrumpí mi formación para estudiar contaduría pública a propósito de la (de) formación contable. Recuperado de http://administracion.univalle.edu.co/Comunidad/ Memorias/evento1/archivos/En\%20mi\%20juventud\%20interrumpi\%20 mi\%20formacion\%20para\%20estudiar\%20contaduria\%20publica.pdf

Ramiro, M. (2005). Ideología y utopía: una aproximación a la conexión entre las ideologías políticas y los modelos de sociedad ideal. Revista de Estudios Políticos (nueva época), 128, 87-128

Reboratti, C. (2000). Ambiente y sociedad. Conceptos y relaciones. Buenos Aires, Argentina: Ariel.

Rincón, P. (2007). Hombre y espacio. Otto Friedrich Bollnow. Análisis crítico. Recuperado de http://servidor-opsu.tach.ula.ve/profeso/maldo_h/1_ analis/hombre_esp.pdf

Rojas, W. y Ospina, C. (2011). Consideraciones sobre el sentido de un proyecto educativo en Contaduría Pública. Cuadernos de Administración, 27(45) 45-60.

Sánchez, D., Moreno, S. y Montoya, N. (2013). Obstáculos de la investigación contable. Una mirada crítica. Letras de Tinta Sangre. Razones y pasiones en la nueva investigación contable. Ponencias XIV Congreso Nacional de Estudiantes de Contaduría Pública de Colombia. Medellín: Yupana/Fenecop.

Sandoval, C. (2002). Enfoques y modalidades de investigación cualitativa. Recuperado de http://www.ecominga.uqam.ca/PDF/BIBLIOGRAPHIE/ GUIDE_LECTURE_7/4/3.Sandoval_Casilimas.pdf.

\section{Para citar este artículo:}

Usma, L. y Torres, S. (2016). Perspectivas de la Educación Contable Desafíos para el reconocimiento de los espacios socioambientales en los programas de Contaduría Pública en la ciudad de Medellín. En-Contexto, 4(5), 207-241. 